\title{
CERCETĂRI ARHEOLOGICE PE TRASEUL AUTOSTRĂZII TRANSILVANIA. MARGINE NATU (JUD. BIHOR) - OBSERVAȚII PRELIMINARE -
}

Cătălin Bem, Mihai Florea, Katia Moldoveanu

\section{RECHERCHES ARCHEOLOGIQUES SUR LE TRAJET DE L'AUTOROUTE TRANSILVANIA. MARGINE NATU (DEP. DE BIHOR) - OBSERVATIONS PRELIMINAIRES -}

\section{Résumé}

Le but principal des nos recherches menées sur le tronçon 3C (Dolea - Margine) de l'autoroute Borş - Braşov, a été d'identifie les potentiels sites archéologiques.

Le site, une station de Barbaricum (fin du II - III p.Chr.), est placé intégralement sur le trajet de l'autoroute entre le $\mathrm{Km} \mathrm{017+300} \mathrm{et} \mathrm{le} \mathrm{Km} \mathrm{017+350.} \mathrm{Pour} \mathrm{tracer} \mathrm{les} \mathrm{limites} \mathrm{du} \mathrm{site} \mathrm{nous} \mathrm{avons} \mathrm{élargi} \mathrm{la}$ surface vers le nord et le sud et vers l'ouest jusqu'au Km 017+500.

Dans cette aire nous avons enregistré 12 fosses brûlées et 13 non-brûlées (fig. 1), de dimensions proches et d'orientation similaires (NNO-SSE, NO-SE). Ce group de sépultures est placé sur la pente ouest d'une petite vallée qui descende dans la vallée Valea Ungurului (Ungatului),

Les fosses sont rectangulaires (les coins arrondis) et même ovale parfois avec les marges concaves. Les dimensions sont comprises entre $82 \times 99 \mathrm{~cm}$ et $190 \times 310 \mathrm{~cm}$, mais les plus fréquentes sont de 100x130 $\mathrm{cm}$. La profondeur ne dépasse jamais $50 \mathrm{~cm}$.

Dans les fosses brûlées (fig. 2-4) on rencontre parfois des charbons de bois. La couleur des parois brûlées varie de rouge jusqu'a brun-rougeâtre; les parois présentent des modifications thermiques sur une profondeur d'environ $15 \mathrm{~cm}$. Mais il y a des fosses $(\mathrm{Cx} 5, \mathrm{Cx} 23, \mathrm{M} 2)$ où les brûlures sont moins évidentes.

L'inventaire des touts les fosses brûlées et non-brûlées est similaire. Des tessons de céramique grossière faiblement cuite et de céramique fine bien cuite de diverses couleurs (rouge, gris et noire); des fragments de quartzite et tuf calcaire. Le seuls matériaux découverts sont un poinçon en cuivre (Cx13) et deux fragments indéterminables en fer (Cx24A, Cx24B).

Mots clef: „Autostrada Borş-Braşov”, fosses réctangulaires, Prszeworsk.

Cuvinte cheie: „Autostrada Borş-Braşov”, gropi rectangulare, Prszeworsk.

Programul Național de Cercetare Arheologică „Autostrada Borş-Braşov”, instituit prin ordinul Ministrului Culturii şi Cultelor 2040/04.02.2004, a implicat obligativitatea realizării de lucrări arheologice având un caracter preventiv şi de salvare, dar şi asumarea responsabilității punctuale şi generale.

Zona studiată în campania anului 2004 de către colectivul Muzeului Național de Istorie a României se situează în prelungirea nordică a Munților Apuseni, reprezentaţi aici prin Muntele Şes, respectiv în extremitatea nordică a acestei zone, ce face parte din depresiunea neogenă Şimleul Silvaniei, din lungul Văii Barcăului (Patrulius et alii 1968).

Muntele Şes prezintă în această zonă altitudini maxime de $600 \mathrm{~m}$, cu creste domoale, datorate unei activități intense de coluviu. Spre nord, altitudinea coboară treptat, către zona depozitelor neogene ce constituie Dealurile Silvaniei şi depozitele cuaternare, care se întâlnesc în lungul Văii Barcăului ce colectează văile ce izvorăsc din versantul nordic şi nordvestic al Muntelui Şes.

În aria cercetată, dealurile prezintă înclinări generale spre nord, fiind tăiate de văi 
înguste, majoritatea reprezentând cursuri temporare.

Sectorul de autostradă (Km 014+000 019+000) care a făcut obiectul cercetării pentru Muzeul Național de Istorie a României (fig. 1) traversează, aşadar, strict o zonă colinară, străbătută de pâraie, afluenți în general temporari ai Barcăului, conferindu-i un aspect general vălurit şi crestat de numeroase văi înguste (fig. 2).

Baza informațională, ca rezultat nedefinit ca atare al studiilor de arheologie preventivă, a avut ca punct de plecare perieghezele din perioada decembrie 2003 - ianuarie 2004 realizate de către specialişti ai Muzeului Țării Crişurilor din Oradea, ale căror rezultate au fost predate Beneficiarului şi Finanţatorului întregului complex de lucrări de construcție, Compania Naţională de Autostrăzi şi Drumuri Naţionale. $\mathrm{Cu}$ excepția acestui studiu preliminar, nu existau în momentul debutului cercetărilor noastre alte informații privind strict zona de interes imediat. Era menționată, pentru fragmentul de tronson supus spre analiză (aproximativ în dreptul Km 017+000 017+300 - fig. 3), o stațiune, la Margine Natu, datată fiind în sec. III-IV p.Chr., zonă care adăpostea şi resturi antropice medievale şi modern-contemporane. Fuseseră descoperite o serie de fragmente ceramice, dar şi de chirpic, care puteau indica aici existența unei aşezări. Cercetările de teren ale echipei MNIR ${ }^{1}$, efectuate în mai multe rânduri (în intervalul aprilie-iulie 2004) au confirmat cele aflate de către colegii orădeni, cu excepția materialelor medievale.

Fixarea definitivă a axului viitoarei autostrăzi, necunoscut exact în iarna 20032004, a lăsat însă mult în afară perimetrul (considerabil, de altfel) din care s-au aflat amintitele fragmente ceramice. Marginea dreapta a autostrăzii este fixată acum în teren la

\footnotetext{
${ }^{1}$ Echipa MNIR care a participat la cercetarea staţiunii de la Margine Natu a fost următoarea - dr. Cătălin Bem responsabil; membri - Mihai Florea, Katia Moldoveanu, Sorin Oanță, Ionuț Fronescu, Mihai Vasile, Andra Samson (MNIR), Dan Turcu (SNSPA), dr. Adrian Bălăşescu, dr. Valentin Radu, Constantin Haită (MNIRCNCP).
}

mai bine de $250 \mathrm{~m}$ sud față de zona identificată ${ }^{2}$ ca potențial sit arheologic (fig. 3).

Trebuie menționat că în spațiul încadrat de marginile autostrăzii, în dreptul aşezării, la suprafața solului nu au fost descoperite fragmente ceramice sau alte elemente care să indice prezența unor intervenții antropice demne de atenția noastră în acest context.

Aşadar, staţiunea nu mai intra în vederile noastre imediate. Microtopografia zonei ne-a obligat însă să acordăm în continuare o atenție deosebită spaţiului ocupat de traseul autostrăzii, în dreptul aşezării amintite.

Prezența unei mici văi (fig. 4), închise din trei părți, care debuşează în Valea Ungurului (pe hărți Valea Ungatului), propice a adăposti resturi antropice, ne-a determinat să realizăm o serie de sondaje. Primele rezultate au justificat insistența noastră. Descoperirile puteau indica prezența unor manifestări contemporane cu aşezarea amintită dar şi cu cea din punctul Sinica, aflată la cca. $700 \mathrm{~m}$ vest, ca şi cea din zona Văii Taniei ${ }^{3}$, situată la cca. 1900 $\mathrm{m}$, de asemenea, spre vest, ambele pe teritoriul aceluiaşi sat şi tot pe traseul autostrăzii.

Spaţiul delimitat de kilometri 017+300 şi 017+350 ai viitoarei autostrăzi, care include descoperirile MNIR - în fapt, ceea ce se numeşte îndeobşte „,câmp de gropi”, se află în proximitatea sud-estică a satului Margine (com. Abram, jud. Bihor), pe panta vestică a văioagei amintite (fig. 4). Concentrarea gropilor se plasează la limita de acutizare relativă a pantei, nedepăşind-o. Întreaga staţiune se află integral pe traseul autostrăzii.

Pentru a verifica eventuale extinderi ale sitului a fost investigată o zonă mai largă, atât uşor în afara traseului (deci, spre nord şi sud) cât şi, mai ales, spre vest, până în jurul Km 017+500. Ca urmare toate secțiunile trasate şi cercetate în punctul Natu au fost integrate acestei staţiuni, deşi marea lor majoritate (în fapt, cu două excepții) nu conțin urme antropice. Trebuie, în plus, consemnat că, exceptând umplutura gropilor, nu există în

\footnotetext{
2 În plus, este situată în dreptul Km $017+350$ $017+500$, nu aşa cum apare pe documentația constructorului, în dreptul Km 017+100 - 017+300.

${ }^{3}$ Cele două stațiunile sunt în curs de cercetare de către colective ale Muzeului Țării Crişurilor din Oradea.
} 
cuprinsul spațiului cercetat de noi alte resturi antropice dintr-o perioadă contemporană sitului în discuție. Cele câteva fragmente ceramice descoperite în zona de vest a punctului Natu (fig. 3) sunt exclusiv de factură modernăcontemporană.

Practic, întreaga zonă de interes a fost cercetată, fiind descoperite 12 gropi arse şi 13 nearse (fig. 5), având dimensiuni asemănătoare şi orientări similare (NNV-SSE, NV-SE).

Numărul mare şi densitatea secțiunilor ${ }^{4}$ trasate şi cercetate de către echipa MNIR ne îndreptățeşte să considerăm că suprafața „câmpului de gropi” este cea surprinsă pe teren.

$\mathrm{Au}$ fost trasate ${ }^{5}$ secțiuni paralele ${ }^{6}$, cu martori de grosime variabilă între ele, dimensiunile dominante fiind $20 \times 1 \mathrm{~m}$ şi o orientare predilectă aproximativ est-vest. În cazul descoperirii de complexe au fost trasate şi cercetate o serie de casete de dimensiuni variabile (care au primit sigle în legătură cu secțiunile cărora sunt adosate şi, dacă era cazul, cu poziția cardinală față de acestea - de ex., CasNS050).

În spațiile libere de secțiuni, în exteriorul zonei de concentrare a complexelor, am procedat şi la realizarea unor carotaje $(\mathrm{cu}$ diametrul de $7 \mathrm{~cm}$ ) organizate pe şiruri paralele sau/şi perpendiculare între ele şi față de secțiuni

\footnotetext{
${ }^{4} \mathrm{Au}$ fost trasate 80 de secțiuni însumând $1158 \mathrm{~m}^{2}$, cărora li se adaugă suprafața totalităţii casetelor deschise strict în zona concentrării gropilor $-1200 \mathrm{~m}^{2}$. Deşi procentul suprafeței cercetate pare mic față de spațiul amintit cuprins între km $017+300-017+500$, nu trebuie să omitem faptul că situl nu depăşeşte $1000 \mathrm{~m}^{2}$, ceea ce implică un procent considerabil - aproximativ 90, fără îndoială, suficient. Între secțiunile cercetate (incluzând casetele deschise) au rămas necercetați martori a căror grosime (de 0.5 sau $1 \mathrm{~m}$ ) nu permite conservarea nici unui complex de acest tip. Aşadar, totalitatea secțiunilor trasate implică acoperirea exhaustivă a zonei de interes arheologic.

5 În cazul unora dintre secțiuni - exclusiv din exteriorul spațiului ocupat de complexe, pentru decaparea stratului vegetal superficial şi a părții superioare a celui de-al doilea nivel, am utilizat şi mijloace mecanice puse la dispoziție de firma constructoare (de ex., în fig. 5 numai S081 a fost decapată mecanic, iar în fig. 6, numai S082, singurele două, de altfel, care au beneficiat de acest tratament).

${ }^{6}$ Inițial, a trebuit să ținem seama, în ceea ce priveşte amplasamentul secțiunilor, de imediata vecinătate a proprietăților private cultivate. Ulterior, amabilitatea proprietarilor ne-a permis extinderea săpăturilor şi o organizare spațială mai coerentă a secțiunilor.
}

(fig. 6). Amplasamentul pe şiruri s-a făcut din metru în metru sau din 2 în $2 \mathrm{~m}$.

Stratigrafia, relevată de totalitatea secțiunilor, se regăseşte şi în cazul carotajelor efectuate aici. Reamintim că, exceptând umplutura gropilor, nu există alte resturi antropice. Similară în general cu cea a întregii zone investigate pe cei cinci kilometri ai tronsonului MNIR, stratigrafia stațiunii cercetate la Margine Natu este extrem de simplă: $1-$ sol actual (prezent în toate secțiunile trasate şi cercetate, are grosimi centimetrice şi este, practic, rezultatul aratului); 2 - silt (argilă siltică) cenuşiu-gălbui, uneori şi cu nuanțe albicioase, în general omogen, compact, bine sortat, cu mici concentrări de hidroxizi de fier; 3 - argilă siltică brun-roşcată sau gălbui-roşcată, foarte compactă, eterogenă, puternic pigmentată cu oxizi de fier şi mangan ${ }^{7}$.

Toate complexele sunt săpate în al treilea nivel şi acoperite de cel de-al doilea. Nu există nici o excepție. Foarte probabil, un nivel de sol antic va fi existat (deci între nivelurile 2 şi 3 ), dar omogenizarea pedogenetică a împiedicat individualizarea sa stratigrafică.

Gropile, rectangulare (având colțurile mai mult sau mai puțin rotunjite - fig. 7-9) sau, mai ales în cazul celor nearse, aproape ovale (fig. 10), cu laturi uneori concave (fig. 11-12), au dimensiuni cuprinse între $82 \times 99 \mathrm{~cm}$ şi 190x310 cm (marginile intervalului constituind, însă, excepții, media dimensională fiind în fapt 100x130 cm). Adâncimea lor nu depăşeşte niciodată $50 \mathrm{~cm}$, fiind cel mai adesea plasată în jurul valorii de $25 \mathrm{~cm}$.

Sunt săpate, aşadar, în argila de vârstă geologică, gălbui-roşcată, umplutura lor fiind acoperită de o argilă siltică (nivelul 2). În unele cazuri, deasupra umpluturii, sub argila siltică, se păstrează o serie de lentile de grosime milimetrică sau sub-milimetrică rezultat al activității pluviale (fig. 13).

În gropile arse se păstrează în unele cazuri, pe fund, fragmente de dimensiuni relative mari de cărbune, mai ales spre colțuri şi de-a lungul pereților (fig. 14-15). Arderea pare să fii avut în unele cazuri o intensitate

\footnotetext{
${ }^{7}$ Cifrele se regăsesc ca atare în fotografii şi planuri/ profile.
} 
apreciabilă - pereții sunt impresionați termic uneori până la 15 cm (fig. 16), gradual, de la roşu-cărămiziu (spre exterior) la brun-roşcat (spre interiorul stratului de argilă). În câteva situații $(\mathrm{Cx} 5, \mathrm{Cx} 23, \mathrm{M} 2)$ arderea a fost mai puțin intensă (fig. 17). Pe fundul acestor gropi, argila în care au fost săpate abia a fost atinsă de foc. Mai mult, marginile superioare ale gropilor, în momentul descoperirii apăreau absolut nearse, benzile care apăreau în cazul unei arderi importante lipsind sau, cel mult, individualizându-se spre partea inferioară a pereților. Gropile nu sunt lutuite; individualizarea cromatică a celor două amintite benzi verticale nu presupune existența vreunei intervenții antropice directe asupra pereților gropii, ci se datorează exclusiv focului (fig. 16). Fragmentele de cărbune sunt integrate unei unităti stratigrafice independente, rezultat al arderii. Mulează pe pereții gropii (fig. 18-19), are la partea superioară, atunci când este cazul, fragmente osteologice, friabile şi de mici dimensiuni, şi este acoperită de un strat constituit din fragmente de argilă arsă care provin din pereți ${ }^{8}$ (fig. 18-19). Umplutura propriu-zisă le acoperă pe toate acestea, fiind similară cu cea a gropilor nearse (fig. 18-20).

$\mathrm{Nu}$ au fost identificate cazuri de suprapunere a complexelor, fapt care, alături de dispunerea acestora pe un contur cel puțin aparent coerent (pentru 23 din cele 25 de gropi) - circular sau relativ rectangular (fig. 5), poate indica fie marcarea la suprafață a gropilor, fie existenţa unei perioade de timp în care acestea au stat deschise. Cea din urmă posibilitate poate fi argumentată şi prin existența în cadrul succesiunii stratigrafice, în cazul gropilor arse, a unei unități, aşa cum am menţionat mai sus, constituite din porțiuni arse ale pereților căzute în interior.

Inventarul este asemănător, fie dacă groapa este arsă, fie dacă nu este. Componenta principală este ceramica (fig. 21/1; 22/1-2), în totalitate fragmentară, dintr-o pastă cu pietriş în compoziție, slab arsă. Alături de acest tip ceramic, mai rar însă, apare o ceramică fină,

\footnotetext{
${ }^{8} \mathrm{O}$ descriere foarte asemănătoare, de ex., la I. Stanciu et alii 2002, în cazul stațiunii de la Lazuri Tubi tag (jud. Satu Mare).
}

dintr-o pastă cu nisip în compoziție, mai bine arsă, la cenuşiu, şi, în sfârşit, extrem de rar, fragmente din pastă fină, fie arse la roşucărămiziu (în legătură cu activitatea ceramică din Imperiu - fig. 21/2), fie arse la negru şi cu suprafața dinspre exterior şlefuită (de factură Prszeworsk). În totalitate, inventarul ceramic, autohton, roman sau de factură Prszeworsk indică o datare a stațiunii în perioada de la sfârşitul sec. II şi sec. III p. Chr. Numeroase fragmente de cuarțit şi gresie (uneori, sparte intenționat) sau tuf calcaros completează un inventar, de altfel, foarte sărac. Un ac fragmentar din cupru (fig. 23), trei fusaiole (fig. 24/3-5) şi două fragmente indeterminabile din fier (fig. 24/1-2) sunt singurele alte materiale descoperite.

O mențiune în plus merită o descoperire din $\mathrm{Cx} 25$, poate una dintre cele mai importante. Toți galeții amintiți mai sus, din cuarțit, gresie sau tuf calcaros, prezenți în toate complexele cercetate, provin din albia Barcăului, râu care actualmente curge la $3.5 \mathrm{~km}$ de situl de la Margine Natu. Dacă aşa stau faptele, atunci micul nucleu neutilizat de obsidian (descoperit în asociere $\mathrm{cu}$ alți 11 galeți de cuarțit), cu suprafața exterioară calcaroasă extrem de rulată, nu poate proveni decât tot din albia Barcăului. Aceasta presupune că râul spală întro zonă din amonte depozite de obsidian. Este, însă, dificil, deocamdată, de a fixa cu exactitate acest spațiu. Cert este faptul că, alături de sursele extrem nord-estice, cursul superior şi mijlociu al Barcăului (sau unul din afluenții săi din amonte de Margine) traversează o posibilă arie sursă pentru obsidian.

Determinarea specifică ${ }^{9}$ a acestei roci, ca şi în cazul altora, a presupus spargerea sa pentru că uniformitatea cortexului calcaros nu permitea alt tip de intervenție. Aşadar, culegerea sa din albia Barcăului nu a vizat tipul rocii în sine ci tipul piesei - galetul.

La începutul cercetării „câmpului de gropi” am crezut că ne aflăm în prezența unei necropole de incinerație - de aceea şi primele sigle ale complexelor descoperite încep cu litera

\footnotetext{
${ }^{9}$ Mulțumim şi pe această cale dlor Constantin Haită (MNIR-CNCP) şi Ionuţ Fronescu (FGB) pentru realizarea determinărilor petrografice.
} 
$M$. Ulterior, s-a constatat că nu există nici o dovadă în sensul apropierii acestor gropi de un anume caracter sepulcral. Singurele resturi osteologice (tab. 1) descoperite, arse (prezente atât în gropi arse cât şi în cele nearse) şi extrem de friabile, aparțin exclusiv mamiferelor domestice.

Îmbogățirea repertoriului de descoperiri de perioadă romană din Barbaricum nu este semnificativă, dar aduce o serie de clarificări în ceea ce priveşte aşa-numitele gropi arse din nord-vestul României. Cazul stațiunii de la Margine Natu este singular în aria românească în care apare acest tip de manifestări - până în prezent, nu a fost identificată nici o situație în care prezența gropilor să fie independentă de construcții domestice sau de alte unități depoziționale (Matei, Stanciu 2000). Gropile arse nu sunt lutuite, cum se afirma până acum, par a fi deschise o anumită perioadă (dacă ținem cont de faptul că umplutura propriu-zisă acoperă fragmente din pereții arşi şi degradați ai gropilor) şi sunt dublate de un număr asemănător de gropi arse, care, chiar dacă nu repetă până la identitate, respectă în mare dimensiunile, orientarea şi structura inventarului celor arse. În plus, ele păstrează în umplutură fragmente, uneori, cum este mai cu seamă cazul Cx25, de lipitură (?) arsă (fără a fi vorba de o ardere in situ).

Fenomenul caracterizat şi de acest gen de descoperiri arheologice este pus în legătură cu vandalii timpurii de tip Prszeworsk. Descoperiri similare jalonează o avansare a manifestărilor de acest tip din Polonia de sud-est spre Slovacia şi Ucraina Transcarpatică (Kotigoroško 1995), Ungaria (Istvánovits 1997) şi nord-vestul României actuale (o sinteză a descoperirilor la Matei, Stanciu 2000). În general, în literatura de limba română de specialitate apar menționate aceleaşi stațiuni - sunt, evident, cele care au beneficiat de cercetări de amploare. Publicarea unor săpături din această perioadă din județul Bihor $^{10}$ face legătura dintre descoperirile din

\footnotetext{
10 Pe lângă descoperiri de acelaşi tip din stațiunea amintită în rândurile noastre de la Margine Valea Taniei, în județul Bihor au mai fost cercetate o serie de stațiuni care indică prezența aceluiaşi fenomen mulțumim şi pe această cale dlui Sorin Bulzan (MȚC Oradea), pentru informațiile oferite cu amabilitate.
}

nord-vestul extrem (județele Maramureş Lăpuşel, de exemplu, și Satu Mare Homorodul de Sus şi Lazuri Lubi tag) şi cele din județul Sălaj, cercetate pe scară largă Parnic Uroikert, Hereclean Dâmbul Iazului, Bocșa La Pietriş, Badon Doaște sau Zalău Bdul. M. Viteazul 104-106. În toate aceste stațiuni, asocierea tipurilor ceramice este identică cu cea de la Margine Natu - ceramică grosieră cu pietriş în pastă, lucrată cu mâna şi în procent majoritar, ceramică negru-cenuşie şi neagră adesea şlefuită, ceramică la roată, fină, cenuşie, mată şi ceramică romană - şi permite o datare sigură în perioada cuprinsă între sfârşitul sec. II şi sec. III p.Chr. (de ex., Stanciu, Matei 2004).

Interpretarea ${ }^{11}$ acestui tip de complexe arheologice este deocamdată dificilă. În ceea ce priveşte gropile arse, noi înşine am crezut că pot fi morminte de incinerație, dar, aşa cum menționam mai sus, în lipsa unor argumente suficiente, am fost obligați să renunțăm curând la această aserțiune. Unii autori le consideră vetre (Kotigoroško 1995), alții numindu-le doar gropi rectangulare $\mathrm{cu}$ pereții arşi (Matei, Stanciu 2000), aceasta nepresupunând însă şi o interpretare explicită, şi, în sfârşit, alți specialişti le consideră afumători ${ }^{12}$. Variabilitatea extremă a interpretărilor nu ne obligă decât la a aştepta noi cercetări care să clarifice această problemă.

$* * *$

Într-o scală a importanței de la 1 la 4, stațiunea de la Margine Natu ar ocupa un penultim loc. Numărul mare de secțiuni şi exhaustivitatea cercetării, care ar fi putut fi evitate în condiții normale, indică, însă, condiția de debutant a acestui gen de abordare a cercetării ştiinţifice. Evident, stabilirea importanței unui sit arheologic devine în unele nedorite cazuri o chestiune absolut subiectivă în lipsa unei scheme foarte clare şi argumentate.

\footnotetext{
11 Nefiind publicate, nu putem da lista completă a interpretărilor.

12 Dan Tamba (MJ Zalău) - în cadrul discuțiilor prilejuite de prezentarea raportului de săpătură Cercetări arheologice pe traseul Autostrăzii BorşBraşov - Margine Natu, la Sesiunea anuală de rapoarte arheologice, Campania 2004, Jupiter 2005.
} 
Importantă este, în alt context, însă, şi descoperirea micului nucleu de obsidian în Cx25, deşi neutilizat. Faptul că totalitatea rocilor din gropi provin din albia Barcăului sau din imediata sa apropiere, nu poate indica decât aceeaşi sursă şi pentru obsidian. $\mathrm{Cu}$ alte cuvinte, Barcăul spală în amonte depozite care conțin sticlă vulcanică. Paradoxal, o descoperire realizată într-o stațiune din sec. II-III p.Chr., este importantă mai cu seamă pentru neoeneoliticul zonei.

Mai multe informații privind fiecare complex în parte, inventarul acestora şi discuții asupra acestui tip de descoperiri vor fi cuprinse într-o lucrare amplă având caracter monografic. Poate definitivarea analizelor micromorfologice şi granulometrice să aducă, de asemenea, un plus de date, să infirme sau să confirme o ipoteză sau alta.

\section{Tab. 1. Determinarea specifică a materialului osteologic ${ }^{13}$ descoperit în stațiunea de la Margine Natu.}

\begin{tabular}{|l|l|}
\hline Complex & Determinare arheozoologică \\
\hline M1 & $\begin{array}{l}\text { - Bos taurus, molar inferior de vârstă subadultă, pe exteriorul acestuia se observă } \\
\text { şi urme care ar putea proveni de la pereții mandibulei. }\end{array}$ \\
\hline Cx9 & $\begin{array}{l}\text { - oase indeterminabile, care sunt arse, de culoare albicioasă (probabil un os lat } \\
\text { având în vedere textura sa internă). }\end{array}$ \\
\hline Cx13 & $\begin{array}{l}\text { - Sus domesticus, 2 falange II, 1 falangă III şi 1 falangă II laterală (deget lateral) } \\
\text { care sunt epifizate şi provin de la un animal în vârstă de 12-24 luni; oasele sunt } \\
\text { arse şi prezintă o culoare albicioasă. } \\
\text { - mamifer de talie medie, diafiză de os lung arsă de culoare albicioasă. }\end{array}$ \\
\hline Cx18 & - mamifer de talie medie, diafiză de os lung arsă de culoare albicioasă. \\
\hline Cx22 & - Sus domesticus, molar inferior (M2), uzură medie, subadult. \\
\hline Cx23 & $\begin{array}{l}\text { - Ovis aries/Capra hircus, femur, epifiză proximală desprinsă, arsă de culoare } \\
\text { albicioasă }\end{array}$ \\
\hline Cx25 & $\begin{array}{l}\text { - Ovis aries/Capra hircus, fragment mandibulă dreapta cu Pd4 (decidual), vârstă } \\
\text { de 12-18 luni. }\end{array}$ \\
\hline
\end{tabular}

\section{BIBLIOGRAFIE}

Kotigoroško 1995 - V. Kotigoroško, Ținuturile Tisei superioare în veacurile III î.e.n. - IV e.n. (perioadele Latène şi romană), Bibl. Thr. 11, Bucureşti, 1995.

Istvánovits 1997 - E. Istvánovits, Some data on the ethnical and chronological determination of the Roman Age population on the Upper Tisza Region, în N. Gudea (Hrsg.), Roemer und Barbaren an den Grenzen des roemischen Dakiens, Zalău, 1997, p. 717-742.

Matei, Stanciu 2000 - Al. Matei, I. Stanciu, Vestigii din epoca romană (sec. II-IV p. Chr.) în spațiul nord-vestic al României, Zalău - Cluj-Napoca, 2000.

Patrulius et alii 1968 - D. Patrulius, M. Lupu, M. Borcoş, Harta geologică. Şimleul Silvaniei, Bucureşti, 1968.

Stanciu, Matei 2004 - I. Stanciu, Al. Matei, Sondajul din aşezarea de la Bocşa - „La pietriş” (com. Bocşa, jud. Sălaj). Contribuții la determinarea etapei de inceput a epocii romane imperiale târzii în nordvestul României, în L. Ruscu, C. Ciongradi, R. Ardevan, Cr. Roman, Cr. Găzdac (eds), Orbis Antiquus. Studia in honorem Ioannis Pisonis, Cluj-Napoca, 2004, p. 755-778.

\footnotetext{
${ }^{13}$ Determinarea specifică a fost realizată de către dl dr. Adrian Bălăşescu (MNIR-CNCP), căruia îi mulțumim şi pe această cale.
} 
Stanciu, Matei 2006 - I. Stanciu, Al. Matei, Un cimitir din perioada de inceput a epocii romane imperiale târzii în nord-vestul României (Badon-,,Doaşte”, com. Hereclean, jud. Sălaj), în C. Gaiu, Cr. Găzdac (ed.), Fontes Historiae. Studia in homorem Demetrii Protase, Bistrița-Cluj-Napoca, 2006, p. 587-607.

Stanciu et alii 2002 - I. Stanciu, L. Marta, I. Stamati, Lazuri, com. Lazuri, jud. Satu Mare, punct Lubi tag, http://www.cimec.ro/Arheologie/cronicaCA2002/rapoarte/default.htm.

\section{LEGENDE DES FIGURES}

Fig. 1. Le tronçon de l'autoroute fouillé par l'équipe du MNIR en 2004 (le point indique l'emplacement de la station de Margine $\mathrm{Natu}$ ).

Fig. 2. La charte géologique de la zone traversée par le tronçon de l'autoroute fouillé par le MNIR en 2004 (d'après D. Patrulius et alii 1968).

Fig. 3. La zone Margine Natu. 1. L'indication initiale de l'emplacement de l'établissement (documentation MTC Oradea-CNADN); 2. L'emplacement réel de l'établissement; 3. L'aire fouillée par MNIR - «le champ de fosses».

Fig. 4. Margine Natu - la limite d'est du «champ de fosses».

Fig. 5. Le plan partiel des fouilles archéologiques de la zone Margine Natu «le champ de fosses».

Fig. 6. Plan partiel des fouilles archéologiques de la zone Margine Natu - sections et carreautages.

Fig. 7. Margine Natu, $\mathrm{Cx} 5$ en cours de recherche.

Fig. 8. Margine Natu. Le plan M1 (légende commune avec la fig. 18).

Fig. 9. Margine Natu, le plan Cx5.

Fig. 10. Margine Natu, le plan $\mathrm{Cx} 1$ et $\mathrm{Cx} 2$.

Fig. 11. Margine Natu, détail du coin de sud-ouest de Cx6/8.

Fig. 12. Margine Natu, Cx9.

Fig. 13. Margine Natu, M1 - lentilles de sédiment résultant de l'activité pluviale.

Fig. 14. Margine Natu, Cx13 - au fond de la fosse se trouve du charbon in situ.

Fig. 15. Margine Natu, détail du Cx20 - fragment de charbon, au long du paroi du nord-est de la fosse.

Fig. 16. Margine Natu, Cx10 détail. On observe facilement la nette limite entre le bord de la fosse (impressionné thermique - a) et son remplissage (b).

Fig. 17. Margine Natu, Cx23.

Fig. 18. Margine Natu, le profil de M1 (pour l'explication de toutes les unites stratigraphiques nous avons inclus dans le dessin et ce qui ne tien pas effectivement de la fosse). 1 - lentilles de sédiments résultant de l'activité pluviale; 2 - le remplissage proprement dit de la fosse; 3 - fragments de terre glaise brûlée tombées des parois de la fosse; 4 - unité stratigraphique qui contient du charbon in situ; 5 - terre glaise brûlée en rouge-brique (ne fait pas partie de la structure de la fosse); 6 - terre glaise brûlée brun-rougeâtre (ne fait pas partie de la structure de la fosse); 7 - fragment de rocs; 8 - fragments céramiques; 9 fragments isolées de charbon (surtout des fosses non brûlées).

Fig. 19. Margine Natu, le profil Cx5.

Fig. 20. Margine Natu, le profil Cx1 et Cx2.

Fig. 21. Margine Natu, céramique - 1. Tasse d'une pâte grossière; 2. Céramique romaine.

Fig. 22. Margine Natu, céramique - 1-2. Tasses fragmentaires d'une pâte grossière.

Fig. 23. Margine Natu, poinçon (?) fragmentaire en cuivre.

Fig. 24. Margine Natu, 1-2. Fragments indéterminables de fer; 3-5. Fusaïoles.

Cătălin Bem, Mihai Florea, Katia Moldoveanu,

Muzeul Naţional de Istorie a României,

Calea Victoriei 12, Bucureşti,

catalinbem@yahoo.com (autorul prezentului text) 